\title{
Influence of CAD/CAM Material and Preparation Design on the Long-term Fracture Resistance of Endocrowns Restoring Maxillary Premolars
}

Influência do material de CAD / CAM e tipo de preparo na resistência à fratura a longo prazo de coroas endodônticas adesivas na restauração de pré-molares superiores

\author{
Ahmed FOAD ${ }^{1}$, Amina HAMDY ${ }^{1}$, Ghada Abd el FATAH ${ }^{1}$, Ahmad ABOELFADL ${ }^{1,2}$ \\ 1 - Ain Shams University- Faculty of Dentistry- Department of fixed Prosthodontics- Cairo- Egypt. \\ 2 - College of Dentistry- Gulf Medical University- Ajman- UAE.
}

\begin{abstract}
Objective: To evaluate the effect of different occlusal preparation designs and CAD/CAM materials on the fracture resistance of maxillary premolars endcrowns. Materials and Methods: sixty-four endodontically treated upper first premolars were randomly divided into four groups according to ceramic materials (Vita Enamic and IPS emax CAD) and occlusal preparation designs (Anatomical and horizontal butt joint). After teeth preparation, the restorations were all made by CAD/CAM system (Cerec MCXL). Half of each group had undergone cyclic fatigue testing of 105 cycles with $50 \mathrm{~N}$ loading force at a frequency of $0.5 \mathrm{~Hz}$ in a mechatronic chewing simulator machine, and then all samples were loaded to fracture using a universal testing machine with a cross head speed of $0.5 \mathrm{~mm}$ / min recording the fracture resistance values in $\mathrm{N}$. The specimens were measured and statistically analyzed using using three-way analyses of variance (ANOVA), followed by serial two-way and one-way ANOVAs at each level of the study. P-values were adjusted for multiple comparisons using BENFORRONI correction and the significance level was set at $\mathrm{P} \leq 0.05$ for all tests. Results: Vita Enamic endocrowns showed higher fracture resistance values than IPS e max specimens. Conclusions: Vita Enamic endocrowns with anatomical preparations were found to be more favourable restoring endodontically treated maxillary premolars.
\end{abstract}

\section{KEYWORDS}

Endocrowns; All-Ceramic; Fracture; Cyclic loading; CAD/CAM.

\section{RESUMO}

Objetivo: Avaliar o efeito de diferentes tipos de preparo oclusal e materiais CAD/CAM na resistência à fratura de coroas endodônticas adesivas em pré-molares. Materiais e Métodos: Sessenta e quatro primeiros pré-molares superiors tratados endodonticamente foram divididos randomicamente em quatro grupos de acordo com os materiais cerâmicos (Vita Enamic e IPS emax CAD) e tipos de preparo oclusal (Recobrimento Incisal Anatômico e Horizontal). Após o preparo dental, as restaurações foram confeccionadas pelo sistema CAD/CAM (Cerec MCXL). Metade de cada grupo foi submetido a testes de fadiga cíclica de 105 ciclos com força de carga de $50 \mathrm{~N}$ a uma frequência de $0,5 \mathrm{~Hz}$ em uma máquina simuladora de mastigação mecatrônica, e então todas as amostras foram submetidas a fratura por uma máquina de teste universal com uma velocidade de $0,5 \mathrm{~mm} / \mathrm{min}$ registrando os valores de resistência à fratura em N. As amostras foram medidas e analisadas estatisticamente usando análises de variância de três fatores (ANOVA), seguidas por ANOVAs de dois fatores e de um fator em cada nível do estudo. Os valores de $\mathrm{p}$ foram ajustados para comparações múltiplas usando a correção BENFORRONI e o nível de significância estabelecido foi de $\mathrm{P} \leq 0,05$ para todos os testes. Resultados: Coroas endodônticas adesivas da Vita Enamic mostraram maiores valores de resistência à fratura do que as amostras de IPS emax. Conclusões: Verificou-se que as coroas endodônticas adesivas da Vita Enamic com preparos com recobrimento incisal anatômico foram mais favoráveis para restaurar os pré-molares superiores tratados endodonticamente.

\section{PALAVRAS-CHAVE}

Coroas endodônticas adesivas; Restaurações totalmente cerâmicas; Carga cíclica; CAD/CAM. 


\section{INTRODUCTION}

$\mathrm{R}$ estoring endodontically treated teeth continues to be a challenge in reconstructive dentistry. Endocrowns have been proved by many authors to be a viable restorative alternative to conventional crowns for endodontically treated molars [1,2].

The endocrown is a "one-piece ceramic construction comprising a circumferential butt margin and a central retention cavity inside the pulp chamber and constructs both the crown and core as a single unit". The main advantages of such approach are utilizing the available surface in the pulp chamber to improve retention through adhesive bonding in addition to conservatism by following the concept of decay-orientated design [3,4]. Pissis [5] was the forerunner of the endocrown technique, describing it as the "monobloc" porcelain technique.

Nowadays the concept of endocrowns have been extended to involve premolars despite the debate regarding their biomechanical behaviour and long-term serviceability. Whether the concept is similarly successful in premolars as proved to be in molars is still controversial. In a clinical study, Bindl et al. [6] evaluated the performance of 208 endocrowns cemented to premolars and molars and observed that the premolars presented more failures than the molars, this might be explained by the fact that the available surfaces for adhesive bonding are more in molars than premolars [1], beside the ratio between the crown base and height causing high leverage for the premolars than molars $[7,8]$. Moreover, Cusp elongation in maxillary premolars due to pulp chamber deroofing in the process of endodontic access cavity preparation tends to separate the buccal and palatal cusps under occlusal load [9].

The recent innovations in ceramic materials and CAD/CAM technologies are developed to enable the accomplishment of high aesthetic demands and to limit the shortcoming of conventional materials and methods; i.e., low tensile strength, sintering shrinkage, excessive brittleness, wear of antagonist, crack propagation [10] and marginal gaps [11]. Nowadays, lithium disilicate material have been widely marketed, because of its adhesive properties [12], being minimilay invasive [13] together with combing ultimate esthetics and clinically successful mechanical behaviour [14].

The ongoing research for a biomimetic material with physico-mechanical properties similar to those of natural tooth structure paved the way to the development of a new generation of hybrid blocks for CAD-CAM processing. The new polymer infiltrated ceramic material (VITA ENAMIC) combines the properties of ceramic and polymer. It consists of "a hybrid structure with two interpenetrating networks of dominating ceramic and a reinforcing composite forming what's called double network hybrid ceramic material" [15].

A variety of occlusal preparation designs in addition to different intrapulpal depths have been suggested in literature [16-19].

Serin Kalay et al in 2016 [18], compared the fracture resistance of restorations with different cusp reduction designs in endodontically treated maxillary premolars. They concluded that anatomic cusp reduction designs exhibited the highest values among other designs.

Taha et al. [16] tested the fracture resistance of different CAD-CAM machinable blocks: lithium disilicate, polymer infiltrated ceramic network vita enamic, cerasmart resin nanceramic and zirconia reinforced lithium silicates ceramics unfired celtra duo. Resin nanoceramics and lithium disilicates had the highest fracture values followed by vita enamic. Moreover, all ceramic endocrowns had acceptable marginal adaptation results having them all suitable for clinical use [16,20].

To date, there is no agreement in literature about which material [21] or preparation design [22] can optimally restore endodontically treated teeth with the best mechanical behaviour $[23,24]$.

Thus, the purpose of this study was to assess the effect of two CAD/CAM materials:(Lithium 
disilicate ceramic (emax CAD) and Polymer infiltrated ceramic network (vita enamic), two occlusal preparation designs (horizontal bevel and anatomical on the fracture resistance of endodontically treated upper premolars restored with endocrown restoration.

The Null hypothesis was that the CAD CAM materials and the occlusal preparation designs wouldn't affect the fracture resistance of endocrowns in upper premolars. While, the aging conditions would affect the fracture resistance of the endocrowns.

\section{MATERIAL AND METHODS}

This research was approved by the committee of Faculty of Dentistry Ain Shams University Research Ethics (FDASU-REC). Recently extracted sixty-four human maxillary first premolars, without caries or visible fracture lines were selected with similar buccolingual (BL) and mesiodistal (MD) dimensions, as determined with a digital caliper allowing a maximum deviation of $10 \%$ from the determined mean. Afterwards teeth were cleaned with ultrasonic scaler (SUPRASSO P5 Booster ultrasonic scaler, Mérignac, France) then stored at room temperature in $0.1 \%$ thymol solution (Caelo, Hilden, Germany). All the teeth were endodontically treated using the same sequence and by the same operator for the purpose of standardization. The pulp chamber was accessed following its own pulp chamber morphology via a round carbide high speed bur. Canal lengths were determined visually by-passing size \#10 K-file through the root canals until being obvious at the apical foramen, working lengths were adjusted $1 \mathrm{~mm}$ short from apical foramen. Protaper system (Dentsply-Maillefer; Ballaigues, Switzerland) was used for root canals treatment for standardization following the manufacturer instruction, F2 were used as master file for both canals, sodium hypochlorite was used as an irrigant after each used file. Protaper paper points and gutta percha size F2 were used. Resin based root canal sealant (ADseal, META BIOMED, Chungbuk, Korea) was used and then a red-hot condenser was used for removal of the excess gutta percha. A surveyor was used to ensure upright position of teeth in molds which were filled with non-shrink epoxy resin material placing the margin of the epoxy resin below the cemento-enamel junction by $3 \mathrm{~mm}$. The selected teeth were randomly divided into four groups $(\mathrm{n}=16)$ according to the margin design and occlusal thickness of the restoration All the endodontically treated teeth were prepared using a Computerized Numerical Control (CNC) milling machine (C.N.C Premium 4820, imesicore, Eiterfeld, Germany) to standardize the preparation dimensions. For all teeth, the CNC milling machine was adjusted to reduce the occlusal surface to yield a pulp chamber with a retention cavity extending $4 \mathrm{~mm}$ from the central groove with 80 divergence of the walls. The preparation criteria for each group are shown in (Figure 1). Group EM B represents teeth that were prepared with a butt joint preparation design and received emax CAD endocrown. GroupEN B represents teeth that were prepared with a butt joint preparation design and received Vita Enamic endocrown. On the other hand, Group EM A represents teeth that were prepared with an anatomical occlusal preparation design and received emax CAD endocrown. GroupEN A represents teeth that were prepared with an anatomical occlusal preparation design and received Vita Enamic endocrown. Endocrown restorations were fabricated using The CEREC AC system (Dentsply Sirona, Bensheim, Germany). Omnicam was used for scanning the preparations and the CEREC premium Software (version 4.4) for designing the restorations. Standardized endocrowns were milled with the Cerec MCXL milling machine. To standardize the form and the anatomy, the design of the restoration was obtained by the sole use of the "position" tools (translation and rotation), with no editing of the original shape produced by the software as shown in (figure 2). Then the restorations were milled from polymer infiltrated ceramics VITA ENAMIC blocks 2M2-T-EM-14 (VITA-Zahnfabrik, Bad Säckingen, Germany), polished using the ENAMIC Polishing Set and from lithium disilicate glass ceramic emax CAD A2 LT(Ivoclar Vivadent, Liechtenstein), finished 
and polished and crystalized as recommended by the manufacturer. Final restorations were measured with a digital caliper for verification of the occlusal thicknesses and the endocore depth extension. The endocrowns were cleaned with $99 \%$ isopropanol in an ultrasonic cleaner for $3 \mathrm{~min}$, while the prepared teeth were cleaned with fluoride-free pumice for $15 \mathrm{~s}$ and rinsed thoroughly with water for $15 \mathrm{~s}$. Etching of the bonding surfaces of the endocrowns was done using $9.5 \%$ hydrofluoric acid gel (Porcelain etch, Ultradent Products, South Jordan, UT, USA) for $60 \mathrm{~s}$ for vita Enamic and $20 \mathrm{~s}$ for emax CAD. The endo-crowns were then rinsed thoroughly for $20 \mathrm{~s}$ then dried with oil free compressed air. The surfaces were then silanized with a primer (Porcelain Silane, Ultradent Products) and left to react for $60 \mathrm{~s}$. The enamel of all preparations was selectively etched for $30 \mathrm{~s}$ with $37.5 \%$ phosphoric acid (Ultra-Etch, Ultradent Products), rinsed, and dried. Self-adhesive resin cement (G cem, GC, Japan) was applied to the fitting surface of the endocrowns which were placed on their relevant preparations by static finger pressure then axially loaded with a $1 \mathrm{~kg}$ load using a specially designed device. The endocrowns were left under the static load for $5 \mathrm{~min}$ then exposed to a brief light curing (Elipar, 3M ESPE) for only $2 \mathrm{~s}$. The excess cement was removed with a scaler, and then light curing was done for $20 \mathrm{~s}$ for each side. The specimens were stored in distilled water at 37 0C for $24 \mathrm{~h}$. Specimens were divided into 2 subgroups:1) tested for fracture resistance and 2) subjected to 100000 chewing cycles of $50-\mathrm{N}$ loading forces at a frequency of $0.5 \mathrm{~Hz}$ using SD Mechatronik, Chewing Simulator, (Willytec, Munich, Germany).

All specimens were loaded vertically on the central fossa of their occlusal surfaces in a universal testing machine (Zwick Z010, Zwick GmbH \& Co, Ulm, Germany) until fracture occurred. The loading piston was centered along the long axis of the specimens with a thrust speed of the machine was $0.5 \mathrm{~mm} / \mathrm{min}$. The breaking load was recorded in Newtons (N). Data were presented as mean and standard deviation (SD) values.
Data were presented as mean and standard deviation (SD) values. Data were explored for normality using KolmogorovSmirnov and Shapiro-Wilk tests and showed normal distribution, so parametric tests were used for the analysis. Homogeneity of variance was assessed using Levene's test and by viewing boxplots of the grouped data no outliers were detected. Statistical analyses were performed with IBM ${ }^{\circledR}$ SPSS ${ }^{\circledR}$ (SPSS Inc., IBM Corporation, NY, USA) Statistics Version 26 for Windows and using three-way analyses of variance (ANOVA), followed by serial two-way and oneway ANOVAs at each level of the study. P-values were adjusted for multiple comparisons using BENFORRONI correction and the significance level was set at $\mathrm{P} \leq 0.05$ for all tests.

\section{RESULTS}

Descriptive statistics of fracture resistance for different groups are listed in Table I and figures 3 and 4 . The mean fracture resistance of all test groups was compared across the following factors: ceramic material, occlusal preparation, aging, and their interactions. Results of the three-way ANOVA showed a significant overall interaction between the three variables $(P=0.005)$. Serial two-way ANOVAs showed that for non-aged samples there was a significant interaction between type of the material and occlusal preparation $(\mathrm{p}=0.006)$. While for aged samples, only type of material had a significant effect on fracture resistance with Vita Enamic (775.06 \pm 71.61$)$ having a significantly higher value than Emax samples $(710.91 \pm 48.22)(p=0.014)$. For samples made with butt preparation, there was a significant effect of material and aging; where Vita Enamic samples (957.57 \pm 195.28$)$ had a significantly higher value than Emax samples (856.70 \pm 169.87) ( $\mathrm{p}=0.006)$ and non-aged samples (1068.98 \pm 107.37$)$ had a significantly higher value than aged samples $(745.29 \pm 70.80)(\mathrm{p}$ $<0.001$ ). While for samples with anatomical preparation, there was a significant interaction between type of material and aging ( $\mathrm{p}<0.001)$. For Emax samples, only aging had a significant 
effect ( $\mathrm{p}<0.001$ ) with non-aged samples (1051.38 \pm 101.99) having a significantly higher value. While for Vita Enamic samples, there was a significant interaction between type of preparation and aging $(\mathrm{p}<0.001)$.

Serial one-way ANOVAs of the significant two-way interactions showed that non-aged Vita Enamic samples made with anatomical preparation (1437.58 \pm 99.45) had a significantly higher values than Emax samples with the same occlusal preparation (1097.79 \pm 97.85) (p < 0.001). While for butt type preparation there was no significant difference between both materials $(\mathrm{p}=0.099)$. Also it showed non aged Vita Enamic samples made with anatomical occlusal preparation (1437.58 \pm 99.45 ) to have a significantly higher value than samples made with butt preparation (1132.99 \pm 86.86) ( $<<0.001)$, while for non-aged Emax samples, there was no significant difference between both types of preparation $(\mathrm{p}=0.594)$. All non-aged samples had significantly higher value than aged samples regardless of other factors $(\mathrm{p}<0.001)$ and there was no significant difference in different parameters within aged samples $(\mathrm{p}>0.05)$.

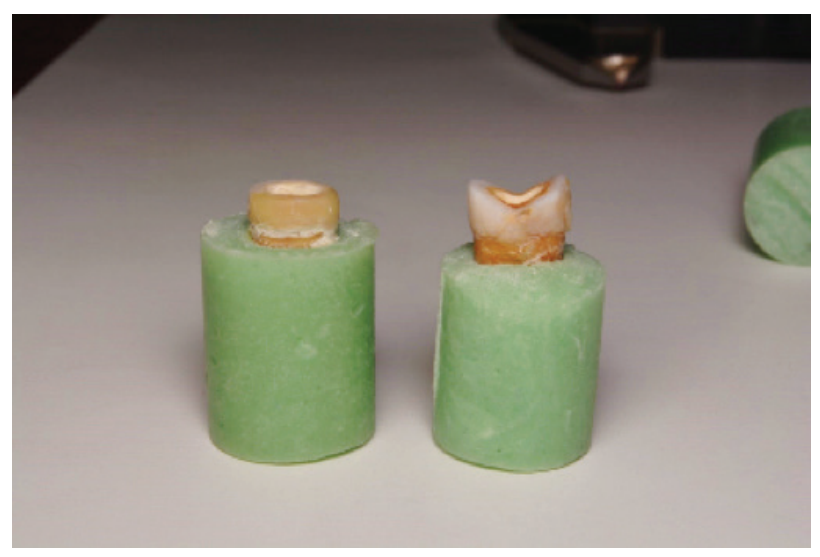

Figure 1 - Different occlusal preparation designs using CNC ((A) Anatomical occlusal preparation and (B) horizontal butt joint preparation).

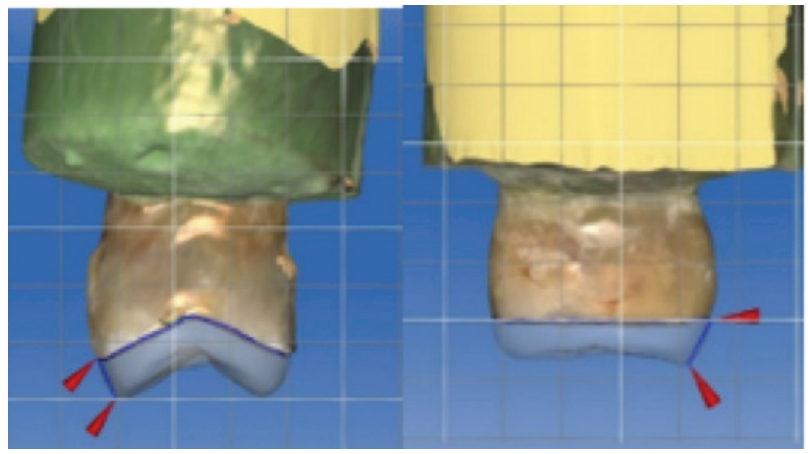

Figure 2 - Different occlusal preparations designs: (A) Anatomical occlusal preparation and (B) horizontal butt joint preparation.

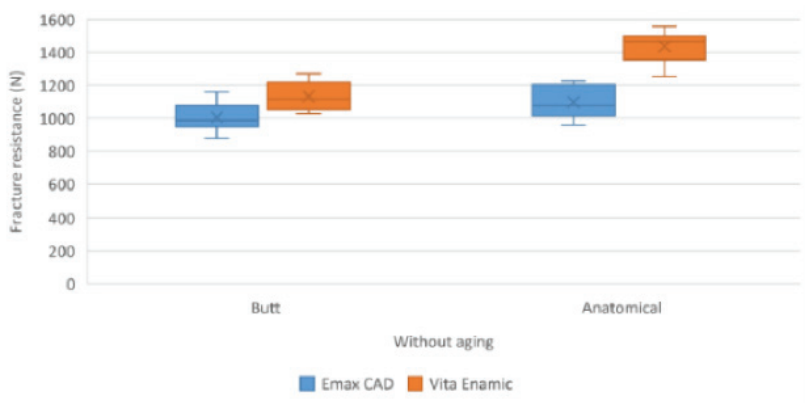

Figure 3 - Box plot showing fracture resistance $(\mathrm{N})$ in non-aged samples.

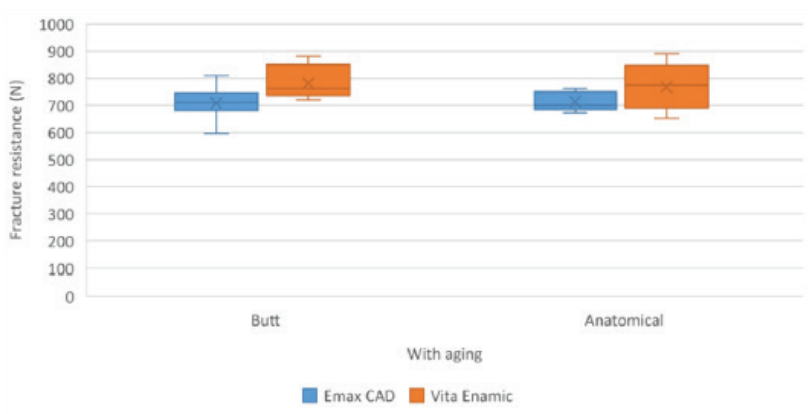

Figure 4 - Box plot showing fracture resistance $(\mathrm{N})$ in aged samples. 
Table I - Descriptive statistics of fracture resistance for different groups.

\begin{tabular}{|c|c|c|c|}
\hline Aging & $\begin{array}{l}\text { Ceramic } \\
\text { material }\end{array}$ & $\begin{array}{l}\text { Occlusal } \\
\text { preparation }\end{array}$ & Mean \pm SD \\
\hline \multirow{4}{*}{ Without aging } & \multirow{2}{*}{ Emax CAD } & Butt & $1004.97 \pm 88.27$ \\
\hline & & Anat. & $1097.79 \pm 97.85$ \\
\hline & \multirow{2}{*}{ VitaEnamic } & Butt & $1132.99 \pm 86.86$ \\
\hline & & Anat. & $1437.58 \pm 99.45$ \\
\hline \multirow{4}{*}{ With aging } & \multirow{2}{*}{ Emax CAD } & Butt & $708.44 \pm 61.63$ \\
\hline & & Anat. & $713.38 \pm 34.20$ \\
\hline & \multirow{2}{*}{ Vita Enamic } & Butt & $782.15 \pm 61.96$ \\
\hline & & Anat. & $767.98 \pm 83.86$ \\
\hline
\end{tabular}

\section{DISCUSSION}

There are no definite preparation guidelines for endodontically treated premolars in literature to guarantee the best biomechanical behaviour. Moreover, the effect of restorative material and the occlusal preparation designs on the fracture resistance are still debatable. Thus, the main purpose of our study was to assess the effect of two CAD/CAM materials (Lithium disilicate ceramic emax and Polymer infiltrated ceramic network vita enamic) and two occlusal preparation designs (horizontal butt reduction and Anatomical reduction) with two aging conditions (No aging and One hundred thousand chewing cycles) on the fracture resistance of endodontically treated upper premolars restored with endocrown restoration. Maxillary premolars were selected in this study to evaluate the success of endocrowns with different designs restoring such teeth with special morphology together with their unique anatomy which is susceptible to cusp deflection [9] and fracture under occlusal loads [25, 26]. Full anatomic restorations were used, because it has been reported that these may allow the restorations to behave in a manner that potentially represents the clinical situation more closely than ceramic discs [27].

Fracture resistance and flexural strength are commonly used to describe the material strength and predict its clinical success or failure [23].
Regarding the results of our study, mean fracture load values for all tested groups were within the range of the maximum chewing forces reported in literature in the posterior area (850N) [28].

Comparing the fracture resistance values of the endocrowns using two CAD/CAM ceramic materials, Serial one-way ANOVAs of the significant two-way interactions showed that non-aged polymer infilterated ceramic network Vita Enamic samples made with anatomical preparation (1437.58 \pm 99.45) had a significantly higher values than lithium Disilicates ceramic Emax samples with the same occlusal preparation (1097.79 \pm 97.85).

This could be explained by the combination of Modulus of elasticity and the high resilience of this polymer infiltrated ceramic (30GPa) which is more comparable to the natural dentin (13.3) in contrast to emax CAD (95GPa). The dual ceramic polymer structure of such hybrid material features integrated crack propagation, uniform stress distribution and shock absorbing capacity. In this context, our results confirm the concept of biomimetics where substrates with similar modulus of elasticity behaves uniformly and integrally in contrast to those of different modulus of elasticity that behaves differently under stress application eventually leading to failure [29].

This is going well with Taha et al [17] who evaluated the fracture resistance of molar endocrowns restored with vita Enamic and concluded that such hybrid material can provide a range of acceptable values of fracture resistance (shoulder finish line with occlusal preparation of $3.5 \mathrm{~mm}$ showed the highest mean fracture load value $(1.27 \pm 0.31 \mathrm{kN})$ while butt joint with $2 \mathrm{~mm}$ occlusal preparation showed the lowest value $(0.88 \pm 0.16 \mathrm{kN}))$. Furthermore, this is following the concept by ZHU J et al in their finite element analysis study, they proved that although using a high elastic modulus material like zirconia or lithium disilicates results in less deformation to load but all the stress where transferred to the remaining teeth structure 
and might lead to further tooth fracture in the future, while the use of a low modulus of elasticity material as leucite material or even composite resin lead to more stress distribution and less stress concentration leading to less tooth fracture and longer survival rate [30].

It's also worth mentioning that the weibull modulus is a critical parameter for ceramics which is used to describe the variability in the material strength. As such the strength is best represented by weibull modulus as a distribution of values rather than a specific value $[31,32]$.

Moreover, our idea of using hybrid ceramic for restoring maxillary premolars have been supported with a systemic review made by Al-Dabbagh et al. [23], confirming that the polymer matrix have a considerable effect in force dissipation and better distribution along the teeth long axis. They stressed on many studies using resin ceramics restoring maxillary premolars confirming their higher fracture strength and lower catastrophic failures than lithium Disilicates ceramics [33-38].

As for the two occlusal surface designs used in our study, non-aged Vita Enamic samples made with anatomical occlusal preparation (1437.58 \pm 99.45) had a significantly higher value than samples made with butt preparation (1132.99 \pm 86.86) ( $\mathrm{p}<0.001$ ), This could be correlated to the better stress distribution and force direction following the original premolar anatomy. Moreover, the anatomical preparation allowed fabrication of a restoration with uniform thickness all over the entire occlusal surface in contrast to the butt joint design which must lead to a lesser ceramic thickness in the central fossa in comparison to the cusp tips area. The difference in the ceramic thickness might lead to stress concentration along the ceramic leading to fracture at earlier load than the thicker uniform anatomical design.

Our results were confirmed by Kalay et al who compared the effect of different occlusal thicknesses and occlusal designs for cusp coverage restoration pestoring endotreated maxillary premolars $(2.5$ mm occlusal thickness with Anatomic preparation design $1110.37 \pm$ $235.05 \mathrm{~N}$ and $2.5 \mathrm{~mm}$ occlusal thickness with horizontal butt joint preparation design 837.24 \pm 207.76), they tested different designs and thicknesses and concluded that adhesive cusp coverage for endotreated maxillary premolars with MOD cavities greatly increased the restoration fracture strength. At least $2.5 \mathrm{~mm}$ was required to achieve a reasonable fracture resistance accompanied with favourable fracture pattern. Anatomical cusp reduction design proved to have better fracture resistance with a favourable fracture pattern due to the axial direction of the cusp reduction design, which would lead to a favorable distribution of occlusal forces and transfer to the tooth structure when a compressive load is applied [18].

The main advantage of a wide occlusal step is to provide a wide stable step for resisting compressive stresses. [39] Various studies proved that anatomical occlusal preparation parallel to the original occlusal surface was the best protocol to have a perfect force distribution along the major tooth axis, [40] leading to stress levels in teeth restored with endocrown restorations much lower than teeth with prosthetic crowns [41,42].

In vitro studies were designed to test different materials, designs or even novel ideas before intraoral application so the conditions of the in vitro study should simulate the clinical intraoral conditions as much as possible which could be achieved through a variety of approaches where aging through mechanical chewing simulator is considered a highly reliable one.

Thus different in vitro aging conditions were suggested to simulate the realistic complex oral environment as thermocycling, acid aging, mechanical and thermomechanical chewing simulators $[43,44]$.

Our study was following a well-known protocol of mechanical aging using mechatronic chewing simulator subjecting the specimens to 100000 chewing cycles $[18,45]$ that represents around 4-5 months of intraoral conditions 
$[43,46]$. In our study all the specimens survived after the chewing simulator indicating that all designs materials have the minimum requirements to withstand the intraoral conditions for at least 4-5 months.

To sum up the results of our study, the null hypothesis was partially rejected, where the CAD CAM materials and the two occlusal preparation designs had shown a significant effect on the fracture resistance values. The null hypothesis was accepted in case of the aging conditions where it had a significant effect on the fracture resistance of endocrown premolars.

\section{CONCLUSIONS}

Within the limitations in this study the following conclusions could be withdrawn:

1. All tested endocrowns showed fracture resistance values within the range of the maximum chewing forces in the posterior area and survived the chewing simulator;

2. Vita Enamic (Polymer Infiltrated Ceramic Network) presented higher fracture resistance in comparison to emax CAD (Lithium disilicates);

3. Anatomical occlusal reduction significantly improved the fracture resistance of endocrowns in upper premolars.

\section{REFERENCES}

1. Sevimli G, Cengiz S, Oruc MS. Endocrowns: review. J Istanb Univ Fac Dent 2015;49(2):57-63. doi:10.17096/jufd.71363

2. Govare N, Contrepois M. Endocrowns: a systematic review. JProsthet Dent. 2020;123(3):411-8.e9. doi:10.1016/.jprosdent2019.04.009

3. Lin CL, Chang YH, Pai CA. Evaluation of failure risks in ceramic restorations for endodontically treated premolar with MOD preparation. Dent Mater. 2011;27(5):431-8. doi:10.1016/j.dental.2010.10.026

4. Bindl A, Mörmann WH. Clinical evaluation of adhesively placed Cerec endocrowns after 2 years--preliminary results. J Adhes Dent. 1999;(3):255-65.

5. Pissis P.Fabrication of a metal-free ceramic restoration utilizing the monobloc technique. Pract Periodontics AesthetDent 1995;7(5):83-94.

6. Bindl A, Richter B, Mörmann WH. Survival of ceramic computer-aided design/ manufacturing crowns bonded to preparations with reduced macroretention geometry. Int J Prosthodont. 2005;18(3):219-24.

7. ZaroneF, Sorrentino R, Apicella D, Valentino B, Ferrari M, Aversa R, etal. Evaluation of the biomechanical behavior of maxillary central incisors restored by means of endocrowns compared to a natural tooth: a3D static linear finite elements analysis. Dent Mater. 2006;22(11):1035-44. doi:10.1016/j. dental.2005.11.034

8. Wu Y,Cathro P,Marino V. Fracture resistance and pattern of the upper premolars with obturated canals and restored endodontic occlusal access cavities. J Biomed Res. 2010;24(6):474-8. doi:10.1016/S1674-8301(10)60063-2

9. Mondelli RF, Ishikiriama SK, de Oliveira Filho 0, Mondelli J. Fracture resistance of weakened teeth restored with condensable resin with and without cusp coverage. J Appl Oral Sci. 2009;17(3):161-5. doi:10.1590/s167877572009000300006

10. Toksavul S, Toman M. A short-term clinical evaluation of IPS Empress 2 crowns Int JProsthodont. 2007;20(2):168-72.

11. Kim JH, Oh S, Uhm SH. Effect of the crystallization process on the marginal and internal gaps of lithium disilicate CAD/CAM Crowns. Biomed Res Int. 2016;2016:8635483. doi:10.1155/2016/8635483

12. Valenti M, Valenti A. Retrospective survival analysis of 261 lithium disilicate crowns in a private general practice. Quintessence Int. 2009;40(7):573-9.

13. ZaroneF,Ferrari M, Mangano FG, Leone R, Sorrentino R. "Digitally Oriented Materials": Focus on Lithium Disilicate Ceramics. Int J Dent. 2016;2016:9840594. doi:10.1155/2016/9840594

14. Stawarczyk B, Liebermann A, Eichberger M, Güth JF.Evaluation of mechanical and optical behavior of current esthetic dental restorative CAD/ CAM composites. JMech Behav Biomed Mater. 2015;55:1-11. doi:10.1016/j. jmbbm.2015.10.004

15. Dirxen C, Blunck U, Preissner S. Clinical performance of a new biomimetic double network material. Open Dent J. 2013;7:118-22. doi:10.2174/1874210620130904003

16. Taha D, Spintzyk S, Sabet A, Wahsh M, Salah T. Assessment of marginal adaptation and fracture resistance of endocrown restorations utilizing different machinable blocks subjected to thermomechanical aging. J Esthet Restor Dent. 2018;30(4):319-28. doi:10.1111/jerd.12396

17. Taha D, Spintzyk S, Schille C, Sabet A, Wahsh M, Salah T, etal. Fracture resistance and failure modes of polymer infiltrated ceramic endocrown restorations with variations in margin design and occlusal thickness. J ProsthodontRes. 2018;62(3):293-7. doi:10.1016/j.jpor.2017.11.003

18. Serin Kalay T, Yildirim T,Ulker M. Effects of different cusp coverage restorations on the fracture resistance of endodontically treated maxillary premolars. J ProsthetDent. 2016;116(3):404-10. doi:10.1016/jprosdent.2016.02.007

19. de Kuijper MCFM, Cune MS, Tromp Y, Gresnigt MMM. Cyclic loading and load to failure of lithium disilicate endocrowns: Influence of the restoration extension in the pulp chamber and the enamel outline. J Mech Behav Biomed Mater. 2020;105:103670. doi:10.1016/j.jmbbm.2020.103670

20. Dartora G, Rocha Pereira GK, Varella de Carvalho R, Zucuni CP, Valandro LF, Cesar PF, etal. Comparison of endocrowns made of lithium disilicate glassceramic or polymer-infiltrated ceramic networks and direct composite resin restorations: fatigue performance and stress distribution. J Mech Behav Biomed Mater.2019;100:103401. doi:10.1016/j.jmbbm.2019.103401

21. Dartora NR, Mauricio Moris IC, Poole SF, Bacchi A, Sousa-Neto MD, Silva-Sousa YT, et al. Mechanical behavior of endocrowns fabricated with different CAD-CAM ceramic systems [published online ahead of print, 2020 Feb 10]. J Prosthet Dent. 2020;S0022-3913(19)30739-5. doi:10.1016/j.prosdent2019.11.008

22. Rocca GT, Daher R, Saratti CM, Sedlacek R, Suchy T, Feilzer AJ, et al. Corrigendum to 'Restoration of severely damaged endodontically treated premolars. The influence of the endo-core length on marginal integrity and fatigue resistance of lithium disilicate CAD-CAM ceramic endocrowns." [J. Dent.68C (2018) 41-50].J Dent. 2018;76:139. doi:10.1016/j.jdent2018.06.011 
23. Al-Dabbagh RA Survival and success of endocrowns: A systematic review and meta-analysis. J ProsthetDent, 2020. D0l:10.1016/.jprosdent2020.01.011. Al-Dabbagh RA. Survival and success of endocrowns: a systematic review and meta-analysis. JProsthetDent. 2020;S0022-3913(20)30079-2. doi:10.1016/j. prosdent.2020.01.011

24. Govare N, Contrepois M. Endocrowns: a systematic review.JProsthet Dent. 2020;123(3):411-8.e9. doi:10.1016/jprosdent2019.04.009

25. Soares PV, Santos-Filho PC, Martins LR, Soares CJ. Influence of restorative technique on the biomechanical behavior of endodontically treated maxillary premolars. Partl: fracture resistance and fracture mode. J Prosthet Dent 2008:99(1):30-7. doi:10.1016/S0022-3913(08)60006-2

26. BurkeFJ. Tooth fracture in vivo and in vitro. J Dent. 1992;20(3):131-9. doi:10.1016/0300-5712(92)90124-u

27. Al-Makramani BMA, Razak AAA, Abu-Hassan Ml. Evaluation of load at fracture of Procera AllCeram copings using different luting cements. J Prosthodont.2008;17(2):120-4. doi:10.1111//.1532-849X.2007.00270.x

28. Apostolov N, ChakalovI, Drajev T.Measurement of the maximum bite force in the natural dentition with a gnathodynamometer.J Med Dental Practice. 2014;(2):70-5.DOl:10.18044/Medlnform.201412.70.

29. EI-Damanhoury HM, Haj-Ali RN, Platt JA. Fracture resistance and microleakage of endocrowns utilizing three CAD-CAM blocks. Oper Dent. 2015;40(2):201-10. doi:10.2341/13-143-L

30. Zhu J, Rong Q, Wang X, Gao X. Influence of remaining tooth structure and restorative material type on stress distribution in endodontically treated maxillary premolars: A finite element analysis. J Prosthet Dent. 2017;117(5):646-55. doi:10.1016/.jprosdent2016.08.023

31. Ritter JE. Predicting lifetimes of materials and material structures. Dent Mater. 1995;11(2):142-6. doi:10:1016/0109-5641(95)80050-6

32. Kelly JR. Perspectives on strength. Dent Mater. 1995;11(2):103-10. doi:10.1016/0109-5641(95)80043-3

33. Hamdy A. Effect of full coverage, endocrowns, onlays, inlays restorations on fracture resistance of endodontically treated molars. J Dent Oral Health [Internet].2015;1(5):1-5. Available from: https://scientonline.org/open-access/ effect-of-full-coverage-endocrowns-onlays-inlays-restorations-on-fractureresistance-of-endodontically-treated-molars.pdf

34. Al-shibri S, Elguindy J. Fracture resistance of endodontically treated teeth restored with lithium disilicate crowns retained with fiber posts compared to lithium disilicate and cerasmart endocrowns: in Vitro. Al-shibriand Elguindy, Dentistry 2017;7:12 doi: 10.4172/2161-1122.1000464

35. Bankoğlu Güngör M, Turhan Bal B, Yilmaz H, Aydin C, Karakoca NemliS Fracture strength of CAD/CAM fabricated lithium disilicate and resin nano ceramic restorations used for endodontically treated teeth. Dent Mater J. 2017;36(2):135-41. doi:10.4012/dmi.2016-017
36. ElGhoul W, Özcan M, Silwadi M, SalamehZ Z Fracture resistance and failure modes of endocrowns manufactured with differentCAD/CAM materials under axial and lateral loading.J Esthet Restor Dent. 2019;31(4):378-87. doi:10.1111/jerd.12486

37. Pedrollo Lise D, Van Ende A, De Munck J,Umeda Suzuki TY, Cardoso Vieira LC, Van Meerbeek B. Biomechanical behavior of endodontically treated premolars using different preparation designs and CAD/CAM materials. JDent. 2017;59:54-61. doi:10.1016/j.jdent2017.02.007

38. Rocca GT, Daher R, Saratti CM, Sedlacek R, Suchy T, Feilzer AJ, et al. Restoration of severely damaged endodontically treated premolars: the influence of the endo-core length on marginal integrity and fatigue resistance of lithium disilicate CAD-CAM ceramic endocrowns. J Dent 2018;68:41-50. doi:10.1016/j.jdent.2017.10.011

39. Zogheib LV, Saavedra Gde S, Cardoso PE, Valera MC, Araújo MA. Resistance to compression of weakened roots subjected to different root reconstruction protocols. J Appl Oral Sci. 2011;19(6):648-54. doi:10.1590/s167877572011000600018

40. Fages M,Bennasar B. The endocrown: a different type of all-ceramic reconstruction for molars. J Can Dent Assoc. 2013;79:d140.

41. Lin CL, Chang YH, Chang CY,Pai CA, Huang SF. Finite element and Weibul analyses to estimate failure risks in the ceramic endocrown and classical crown for endodontically treated maxillary premolar. Eur J Oral Sci. 2010;118(1):87-93. doi:10.1111/j.1600-0722.2009.00704.x

42. Dejak B,Młotkowski A.3D-Finite element analysis of molars restored with endocrowns and posts during masticatory simulation. Dent Mater. 2013;29(12):e309-e17.doi:10.1016/j.dental.2013.09.014

43. Zahran M, El-Mowafy 0, Tam L, Watson PA, Finer Y.Fracture strength and fatigue resistance of all-ceramic molar crowns manufactured with CAD/CAM technology.JProsthodont. 2008;17(5):370-7. doi:10.1111/.1532849X.2008.00305.X

44. Kelly JR, Cesar PF, Scherrer SS, Della Bona A, van NoortR, Tholey M, et al. ADM guidance-ceramics: Fatigue principles and testing. Dent Mater. 2017;33(11):1192-1204. doi:10.1016/j.dental.2017.09.0

45. Rocca GT,Sedlakova P,Saratti CM, Sedlacek R, Gregor L, Rizcalla N, etal Fatigue behavior of resin-modified monolithic CAD-CAM RNC crowns and endocrowns. Dent Mater. 2016;32(12):e338-e350. doi:10.1016/j. dental.2016.09.024

46. Gwon B,Bae EB, Lee JJ,Cho WT,Bae HY,Choi JW, etal. Wear characteristics of dental ceramic cad/cam materials opposing various dental composite resins. Materials (Basel). 2019;12(11):1839. doi:10.3390/ma12111839

\section{Ahmed Foad (Corresponding address)}

Organization of African Unity Street, Cairo, Egypt.

E-mail: Ahmed.Fouad@dent.asu.edu.eg
Date submitted: 2020 Feb 18

submission: 2020 May 20 